\title{
ОСОБЕННОСТИ ВЛИЯНИЯ ХИМИЧЕСКИХ СРЕДСТВ
}

\section{ЗАЩИТЫ РАСТЕНИЙ НА ДИНАМИКУ ЭЛЕМЕНТОВ ПИТАНИЯ В РАСТЕНИЯХ, ИХ ХИМИЧЕСКИЙ СОСТАВ И УСЛОВИЯ РАЗВИТИЯ}

\author{
СПИРИдОНОВ Юрий Яковлевич, Всероссийский научно-исследовательский институт \\ фитопатологии
БУДЫнков Николай Иванович, Всероссийский научно-исследовательский институт фитопатологии

дудкин Игорь Витальевич, Курский научно-исследовательский институт

агропромышленного производства

СТРИжкОВ Николай Иванович, ФГБНУ «НИИСХ Юго-Востока»

СУМИНОВА Наталья Борисовна, Саратовский государственный аграрный университет имени Н.И. Вавилова

\begin{abstract}
НИКОЛАЙЧЕНКО Наталия Викторовна, Саратовский государственный аграрный университет имени Н.И. Вавилова
\end{abstract}

ДАУЛЕТОВ Махат Аскарбекович, Саратовский государственный аграрный университет имени Н.И. Вавилова

ЛЕНОВИЧ Дарья Рудольфовна, Саратовский государственный аграрный университет имени Н.И. Вавилова

\begin{abstract}
Рассмотрены результаты применения гербицидов и инсектицидов на культурах, возделываемых в Поволжве, их влияние на процессы, происходящие в растениях, изменение химического состава и длины вегетационного периода. Применение гербицидов положительно сказалось на химическом составе вегетативной массы яровой пшеницы. Содержание азота через месяи, после внесения было на 0,07 мг\% выше контроля, фосфора - на 0,16 мг\%. К уборке на делянках с применением гербицидов содержание всех питательных веществ превышало контроль. Большое влияние на содержание питательных веществ оказывают погодные условия вегетационного периода. Наименьшее количество азота и калия отмечалось в вегетативной массе культур в благоприятные годы. Наиболее интенсивное снижение нитратного азота после внесения химических средств защиты растений происходит в сухие годы. Содержание нитратного азота, фосфора, калия в зерне проса, яровой пшеницы, нута, кориандра и овса на вариантах с применением химических средств защиты растений (гербицидов, инсектицидов) было на уровне контроля или превосходило его. Установлено, что гербициды и инсектициды не оказывали отрицательного влияния на условия развития растений, биохимические процессы в них.
\end{abstract}

Введение. Фитосанитарное состояние агроценозов в Поволжье, несмотря на принимаемые меры, не улучшается. Главные причины этого - внедрение нулевой и минимальной обработок почвы, несоблюдение севооборотов, несбалансированное внесение минеральных удобрений, недостаточное и неправильное применение пестицидов, несоблюдение технологий возделывания культур $[1,2,8,10,13]$. В нашем регионе мы не добираем в зависимости от засоренности полей до трети урожая зерновых культур, а пропашных, нута и проса до 50 \%. В отдельные годы при отсутствии мер борьбы с ними до $90 \%[2,3,5,7,11]$. Урожайность можно значительно увеличить путем предотвращения потерь от болезней, вредителей и сорняков $[4,6,9,12]$.

Современный ассортимент пестицидов позволяет защищать от вредных объектов посевы практически всех сельскохозяйственных культур. Поэтому в защите растений, наряду с экономической и хозяйственной целесообразностью применения препаратов, первостепенной ста- новится проблема поиска новых экологически безопасных средств и приемов борьбы с сорняками и вредителями. Прибавка урожая как результат химического воздействия - это функция биологической активности пестицида (степени уничтожения им вредоносных объектов) и его фитотоксичности для культуры. Поэтому для разработки эффективных мер борьбы с сорной растительностью и вредителями были заложены опыты.

Цель исследований - определить воздействие гербицидов и инсектицидов на динамику основных элементов питания в растениях, их химический состав, прохождение фенофаз.

Методика исследований. Полевые опыты проводили в 2010-2016 гг. на полях НИИСХ Юго-Востока (г. Саратов), расположенных в зоне засушливой черноземной степи Поволжья, которая характеризуется проявлением засухи и опасностью ветровой эрозии.

Годовая сумма осадков в черноземно-степной зоне Правобережья составляет 420-480 мм. 
За вегетационный период выпадает 200-250 мм осадков. Сумма активных температур выше $+10{ }^{\circ} \mathrm{C}$ составляет $2400-2800{ }^{\circ} \mathrm{C}$. Среднегодовая температура воздуха $4,1-5,2{ }^{\circ} \mathrm{C}$. Продолжительность безморозного периода 115-125 дней, вегетационного 160-165 дней. Погодные условия в годы исследований в полной мере охватывали всю совокупность климатических особенностей региона, отличающихся разнообразием.

Почва опытного поля НИИСХ Юго-Востока - чернозем южный среднемощный тяжелосуглинистый. Пахотный слой характеризуется следующими показателями: содержание гумуса (по Тюрину) - 4,56 \%, азота в пахотном слое $0,238 \%$, валового фосфора - 0,127 \%. Сумма поглощенных оснований в горизонте А - 40,0 мг/экв. на 100 г почвы, $\mathrm{pH}$ 7,0. Наименьшая влагоемкость (НВ) слоя 0-30 см составляет 111,9 мм, 0-100 cм 354,6 мм, 0-150 см - 514,9 мм. Площадь опытной делянки - $1710 \mathrm{~m}^{2}$, повторность 3-кратная, расположение делянок в опыте последовательное. Агротехника возделывания культуры общепринятая для зоны Поволжья.

В наших опытах максимальное количество нитратного азота, фосфора, обменного калия в растениях отмечали в период всходов. На посевах, обработанных гербицидами, содержалось больше нитратов, чем на контроле. По мере роста растений содержание питательных веществ снижалось и к уборке достигало минимума, а там, где применялись гербициды, превышало контроль. Обработка посевов пшеницы гербицидами сказывалась на химическом составе урожая зеленой массы растений. Содержание азота на гербицидном варианте через месяц после внесения в среднем за годы исследований было на 0,07 мг\% выше контроля. Содержание фосфора в зеленой массе экспериментального варианта на 0,016 мг\% превышало контроль, а калия - на 0,08 мг\% (табл. 1).

Ряд гербицидов изменяют активность клеточных ферментов, действуя на них прямо или косвенно. В первом случае молекулы гербицида взаимодействуют с веществами клеточных ядер, конкурируют с субстратом за активные места на молекулах ферментов. Образуют комплексные соединения с ферментами или с их субстратами, что в одних условиях подавляет, а в других - стимулирует активность ферментов. Гербицид может конкурировать с кофакторами ферментативных белков: изменять состояние белкового кофактора и предотвращать активную связь его с протеиновой частью фермента.

Установлено положительное влияние гербицидов на содержание азота в растениях. Более высокое содержание азота на 0,1 мг\% при применении гербицидов отмечали в уборку. В среднем за годы исследований содержание фосфора в растениях яровой пшеницы на протяжении всего вегетативного периода изменялось
Содержание в культурных растениях яровой мягкой пшеницы (Саратовская 42) элементов питания, мг \%, при различных методах борьбы с сорняками (среднее за 2010-2016 гг.)

\begin{tabular}{|c|c|c|c|c|c|c|}
\hline \multirow[b]{2}{*}{$\begin{array}{c}\text { Срок } \\
\text { взятия проб }\end{array}$} & \multicolumn{2}{|c|}{$\mathrm{N}$} & \multicolumn{2}{|c|}{$\mathrm{P}$} & \multicolumn{2}{|c|}{$\mathrm{K}$} \\
\hline & 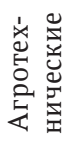 & 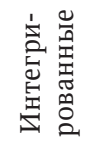 & 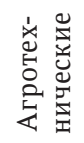 & 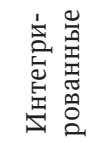 & 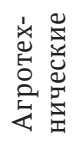 & 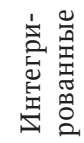 \\
\hline \multirow{3}{*}{ Кущение } & \multicolumn{6}{|c|}{ Сухие годы } \\
\hline & 2,91 & 2,78 & 0,913 & 0,927 & 2,93 & 2,85 \\
\hline & & $-0,13$ & & 0,014 & & $-0,8$ \\
\hline \multirow{2}{*}{$\begin{array}{l}\text { Через месяц } \\
\text { после внесения }\end{array}$} & 1,93 & $-1,95$ & 0,615 & $-0,631$ & 1,42 & 1,52 \\
\hline & & $+0,02$ & & $+0,016$ & & 0,13 \\
\hline \multirow{2}{*}{ В уборку } & 1,57 & 1,69 & 0,620 & 0,619 & 1,14 & 1,18 \\
\hline & & $+0,12$ & & $-0,001$ & & $+0,04$ \\
\hline \multirow{3}{*}{ Кущение } & \multicolumn{6}{|c|}{ Благоприятные годы } \\
\hline & 1,74 & 1,85 & 0,924 & 1,013 & 2,29 & 2,37 \\
\hline & & $+0,11$ & & 0,089 & & $+0,10$ \\
\hline \multirow{2}{*}{$\begin{array}{l}\text { Через месяц } \\
\text { после внесения }\end{array}$} & 1,53 & 1,64 & 0,828 & 0,089 & 1,25 & 1,29 \\
\hline & & $+0,11$ & & $+0,016$ & & $+0,04$ \\
\hline \multirow{2}{*}{ В уборку } & 1,35 & $+1,43$ & 0,682 & 0,686 & 0,75 & 0,85 \\
\hline & & $+0,08$ & & $+0,004$ & & $+0,10$ \\
\hline \multirow{3}{*}{ Кущение } & \multicolumn{6}{|c|}{ Среднее за годы исследований } \\
\hline & 2,33 & 2,32 & 0,919 & 0,970 & 2,56 & 2,61 \\
\hline & & $-0,01$ & & $+0,051$ & & $+0,05$ \\
\hline \multirow{2}{*}{$\begin{array}{l}\text { Через месяц } \\
\text { после внесения }\end{array}$} & 1,73 & 1,80 & 0,722 & 0,738 & 1,34 & 1,42 \\
\hline & & $+0,07$ & & $+0,016$ & & $+0,08$ \\
\hline \multirow{2}{*}{ В уборку } & 1,46 & 1,56 & 0,652 & 0,655 & 0,95 & 1,02 \\
\hline & & $+0,10$ & & $+0,003$ & & $+0,07$ \\
\hline
\end{tabular}

незначительно (от 0,970 \% перед опрыскиванием до $0,738 \%$ через месяц после внесения и до $0,653 \%$ в уборку, что на $0,003 \%$ превосходило контрольный вариант). Гербициды не оказывали отрицательного влияния на изменение содержания в растениях обменного калия. Его в уборку в среднем за годы исследований было в 2,56 раза меньше, чем в кущение, но та же закономерность сохранялась. Под влиянием гербицидов обменного калия на экспериментальной делянке было на 0,07 мг\% выше контроля.

Исследования показали, что содержание нитратного азота, подвижного фосфора и обменного калия при применении гербицидов в значительной степени зависит от погодных условий. В благоприятные годы количество азота и калия в растениях на гербицидных и контрольных делянках было минимальным по сравнению со средними и сухими годами. Так, содержание азота в благоприятные годы на контроле составило 1,74 мг, в сухие - 2,91 мг, что на 67,0 \% выше, чем в благоприятные годы. Наиболее интенсивно снижение нитратного азота после внесения происходит в сухие годы. Интенсивность снижения азота на этих вариантах в 3 раза превосходила этот показатель по сравнению с благоприятными годами. Аналогичная ситуация сложилась и по содержанию подвижного фосфора. Наибольшая интенсивность его снижения, как и азота, отмечалась в сухие годы. Содержание обменного калия снижалось во все годы в 2 раза и более. Следова- 
тельно, гербициды не оказывали отрицательного влияния на содержания азота, фосфора и калия. В начальный период развития яровой пшеницы перед опрыскиванием содержание азота на контрольном варианте было даже более высоким, чем в экспериментальном варианте.

В большинстве случаев гербициды положительно влияют на содержание NPK в растениях. Количество нитратного азота, фосфора, калия в зерне проса, яровой пшеницы, нута, кориандра, овса при уборке урожая повышалось или было на уровне контроля (табл. 2).

Таблица 2

Влияние разных методов борьбы с сорняками на содержание азота, фосфора, калия в зерне, мг \%

\begin{tabular}{|c|c|c|c|}
\hline Вариант & $\mathrm{N}$ & $\mathrm{P}$ & $\mathrm{K}$ \\
\hline \multicolumn{4}{|l|}{ Просо } \\
\hline Агротехнические методы & 1,34 & 1,030 & 0,39 \\
\hline То же + гербициды & 1,60 & 0,850 & 0,45 \\
\hline \multicolumn{4}{|l|}{ Яровая пшеница } \\
\hline Агротехнические методы & 1,80 & 1,015 & 0,50 \\
\hline То же + гербициды & 2,32 & 1,035 & 0,44 \\
\hline \multicolumn{4}{|l|}{ Нут } \\
\hline Агротехнические методы & 2,96 & 1,270 & 1,40 \\
\hline Агротехнические методы + удобрения & 3,18 & 1,215 & 1,34 \\
\hline Агротехнические методы + гербициды & 3,24 & 1,465 & 1,40 \\
\hline $\begin{array}{l}\text { Агротехнические методы + удобрения } \\
+ \text { гербициды }\end{array}$ & 3,44 & 1,220 & 1,35 \\
\hline \multicolumn{4}{|l|}{ Кориандр } \\
\hline Агротехнические методы & 1,18 & 1,24 & 1,85 \\
\hline Агротехнические методы + гербициды & 2,34 & 1,30 & 1,88 \\
\hline \multicolumn{4}{|l|}{$\begin{array}{l}\text { Овес } \\
\end{array}$} \\
\hline Агротехнические методы & 1,90 & 0,61 & 0,68 \\
\hline Агротехнические методы + гербициды & 2,02 & 0,62 & 0,69 \\
\hline
\end{tabular}

При использовании препаратов количество питательных элементов, в первую очередь азота, на посевах нута было на 0,29 мг\% выше контроля, фосфора - на уровне контроля или превосходило его на 0,231 \%. Применение различных доз пульсара на посевах нута подтверждает те же закономерности, что и в севообороте. Минимальные дозы улучшают эти показатели, оптимальные - держат их на уровне контроля, кроме азота, содержание которого превосходит контрольный вариант. Дозы, превышающие разрешенные, значительно снижают содержание азота, не влияя негативно на другие показатели. Большое влияние дозы препарата оказывают на содержание калия. При применении минимальных доз его содержание находится выше контроля, а при оптимальных и максимально разрешенных дозах находится на уровне контроля (табл. 3).

В зерне озимой, яровой мягкой, твердой пшеницы, овсе и кориандре под влиянием инсектицидов содержание общего азота, как правило, возрастает. Инсектициды не оказывают отрицательного влияние на изменение количества подвижного фосфора и обменного калия. В зерне проса содержание общего азота под влиянием гербицида возрастает, фосфора - чаще понижа-
Таблица 3

Влияние различных доз препаратов на содержание азота, фосфора, калия в зерне нута, мг\%

\begin{tabular}{|l|c|c|c|}
\hline \multicolumn{1}{|c|}{ Вариант } & $\mathrm{N}$ & $\mathrm{P}$ & $\mathrm{K}$ \\
\hline Агротехнические методы & 3,42 & 1,200 & 1,201 \\
\hline $\begin{array}{l}\text { Агротехнические методы + минимальная } \\
\text { доза гербицида }\end{array}$ & 3,94 & 1,379 & 1,400 \\
\hline $\begin{array}{l}\text { Агротехнические методы + оптимальная } \\
\text { доза гербицида }\end{array}$ & 3,58 & 1,209 & 1,206 \\
\hline $\begin{array}{l}\text { Агротехнические методы + максимальная } \\
\text { доза гербицида }\end{array}$ & 3,19 & 1,269 & 1,250 \\
\hline
\end{tabular}

Примечание: использование гербицида с действующим веществом имазамокс.

ется, а калия - подвержено незначительным колебаниям в ту или иную сторону.

В наших исследованиях применение гербицидов на озимой, яровой мягкой и яровой твердой пшеницах, кукурузе, просе, ячмене, кориандре, овсе не задерживало прохождение фенологических фаз. На посевах нута при применении почвенных гербицидов наступление очередных фаз в отдельных случаях, когда применялись максимальные дозы, было сдвинуто на 1-2 дня. При использовании повсходовых гербицидов на нуте очередные фазы после их применения наступали на 10-15 дней позже. Была установлена прямая зависимость: чем выше доза препарата, тем позже наступает фаза цветения - полной спелости зерна, хотя на урожайности это негативно не отражалось.

Заключение. Многолетние данные свидетельствуют о перспективности применения гербицидов и инсектицидов. Они не ухудшают условия развития растений, не нарушают протекающие в них биохимические процессы; позволяют получать экологически чистое, полноценное по химическому составу зерно.

\section{СПИСОК ЛИТЕРАТУРЫ}

1. Агроэкологические аспекты применения химических средств защиты посевов проса от сорных растений в Саратовском Правобережье / М.А. Даулетов [и др.] // Аграрный научный журнал. - 2017. - № 9. - С. 3-9.

2. Агрофизические свойства черноземов Кубани и урожайность озимой пшеницы в зависимости от технологии возделывания / В.М. Кильдюшкин [и др.] // Аграрный научный журнал. - 2017. - № 7. - С. 25-28.

3. Влияние химических средств защиты на обменные процессы в растениях, их химический состав, прохождение фенофаз / В.Б. Лебедев [и др.] // Вестник Саратовского госагроуниверситета им. Н.И. Вавилова. - 2007. - № 5. - С. 18-20.

4. Возделывание льна с применением Секатора турбо, Фуроре супер, Баритона и других препаратов в условиях Поволжья / Ю.Я. Спиридонов [и др.] // АПК России. - 2017. - Т. 24. - № 2. - С. 308-313.

5. В расчете на комбинированный тип засоренности / В.Б. Лебедев [и др.] // Защита и карантин растений. - 2004. - № 2. - С. 41-42.

6. Интегрированная технология защиты посевов полевых культур от болезней, вредителей и сорняков на основе биологических и химических методов / Н.И. Стрижков [и др.]. - Саратов, 2017. - 56 с. 
7. Применение препарата Гермес при возделывании подсолнечника / Ю.Я. Спиридонов [и др.] // АПК России. - 2017. - Т. 24. - № 2. - С. 303-307.

8. Продуктивность расторопши пятнистой в зависимости от способов обработки почвы и химических средств защиты в сухой степи Поволжья / М.Н. Худенко [и др.] // Аграрный научный журнал. - 2016. № $12 .-$ С. $43-49$.

9. Разработка интегрированной технологии защиты посевов полевых культур от болезней, вредителей и сорняков на основе биологических и химических методов / Ю.Я. Спиридонов [и др.] // Аграрный научный журнал. - 2017. - № 9. - С. 37-42.

10. Разработка технологии борьбы с вредными организмами с помощью Секатора турбо, Ламадора, Фалькона и других препаратов в посевах яровой пшеницы / Ю.Я. Спиридонов [и др.] // АПК России. 2017. - T. 24. - № 3. - С. 636-642.

11. Технология возделывания яровой твердой пшеницы с применением препаратов Секатор турбо, Баритон, Фалькон, Нагро и других / Ю.Я. Спиридонов [и др.] // Аграрный научный журнал. - 2017. № 3. - С. 30-36.

12. Экологические аспекты формирования систем земледелия и защиты растений / И.В. Дудкин [и др.] // Вестник Курской государственной сельскохозяйственной академии. - 2017. - № 7. - С. 2-7.

13. Nikolaichenko N.V., Eskov I.D., Muraveva M.V., Strizhkov N.I., Azizov Z.M. Productivity and plant protection from diseases and pests of milk thistle (variety amulet) in chernozems in the steppe zone of the Volga region // Journal of Pharmaceutical Sciences and Research, 2017, T. 9, No. 7, P. 1164-1168.

Спиридонов Юрий Яковлевич, $\partial-p$ биол. наук, проф., зав. отделом гербологии, Всероссийский научноисследовательский институт фитопатологии. Россия.

Будынков Николай Иванович, канд. биол. наук, ведущий научный сотрудник лаборатории экологии микроорганизмов, Всероссийский научно-исследовательский институт фитопатологии. Россия.

143050, Московская обл., Одинщовский $p$-н, p.n. Большие Вяземы, ул. Институт, 5.

Тел.: (495) 597-42-28.

Дудкин Игорь Витальевич, ведущий научный сотрудник отдела растениеводства, Курский научно-исследовательский институт агропромышленного производства. Россия.

305526, Курская обл., Курский р-н, пос. Черемушки, 108.

Тел.: (4712) 59-54-85; e-mail: kniiapp@mail.ru.

Стрижков Николай Иванович, $\partial-p$ c.- $x$. наук, главный научный сотрудник лаборатории защиты растений, ФГБНУ «НИИСХ Юго-Востока». Россия.

410010, г. Саратов, ул. Тулайкова, 7.

Тел.: (8452) 64-74-39; e-mail:raiser-saratov@mail.ru.

Суминова Наталья Борисовна, канд. с.-х. наук, доцент кафедры «Защита растений и плодоовощеводство», Саратовский государственный аграрный университет имени Н.И. Вавилова. Россия.

Николайченко Наталия Викторовна, $\partial-p$ c. $-x$. наук, проф. кафедры «Защита растений и плодоовощеводство», Саратовский государственный аграрный университет имени Н.И. Вавилова. Россия.

Даулетов Махат Аскарбекович, канд. с.-х. наук, старший преподаватель кафедры «Ботаника, химия и экология», Саратовский государственный аграрный университет имени Н.И. Вавилова. Россия.

Ленович Дарья Рудольфовна, аспирант кафедры «Защита растений и плодоовощеводство», Саратовский государственный аграрный университет имени Н.И. Вавилова. Россия.

410012, г. Саратов, Театральная пл., 1.

Тел.: (8452) 64-79-50.

Ключевые слова: гербициды; инсектициды; элементы питания в растениях; химический состав; фенофазы; яровая пшеница; нут; кориандр; овес.

\section{FEATURES OF THE INFLUENCE OF CHEMICAL PLANT PROTECTION PRODUCTS ON THE DYNAMICS OF NUTRIENTS IN PLANTS, THEIR CHEMICAL COMPOSITION AND CONDITIONS OF DEVELOPMENT}

Spiridonov Yuriy Yakovlevich, Doctor of Biological Sciences, Academician, Professor, Head of the department of herbology, AllRussian Scientific Research Institute for Experimental Physics. Russia.

Budynkov Nikolay Ivanovich, Candidate of Biological Sciences, Leading Researcher of the laboratory of microorganism ecology, AllRussian Scientific Research Institute for Experimental Physics. Russia.

Dudkin Igor Vitalyevich, Leading Researcher of the laboratory of microorganism ecology, All-Russian Scientific Research Institute for Experimental Physics. Russia.

Strizhkov Nikolay Ivanovich, Doctor of Agricultural Sciences, Senior Researcher of the laboratory of plant protection, Agricultural State Research Institute for South-East Region. Russia.

Suminova Natalya Borisovna, Candidate of Agricultural Sciences, Associate Professor of the chair "Plant Protection and Horticulture", Saratov State Agrarian University named after N.I. Vavilov. Russia.

Nikolaychenko Natalya Viktorovna, Doctor of Agricultural Sciences, Professor of the chair "Plant Protection and Horticulture", Saratov State Agrarian University named after N.I. Vavilov. Russia.

Dauletov Makhat Askarbekovich, Candidate of Agricultural Sciences, Senior Teacher of the chair "Botany, Chemistry and Ecology", Saratov State Agrarian University named after N.I. Vavilov. Russia.

Lenovich Darya Rudolphovna, Post-graduate Student of the chair "Botany, Chemistry and Ecology", Saratov State Agrarian University named after N.I. Vavilov. Russia.
Keywords: herbicides; insecticides, nutrients in plants; chemical composition; phenophase; spring wheat; chickpea; coriander; oats.

The results of application of herbicides and insecticides in crops cultivated in the Volga region, their influence on processes occurring in plants, changes in the chemical composition and length of the vegetation period are considered. Application of herbicides had a positive effect on the chemical composition of the vegetative mass of spring wheat. The nitrogen content was $0.07 \mathrm{mg} \%$ higher than in the control, phosphorus content was $0.16 \mathrm{mg} \%$ higher. By harvesting in plots where herbicides were used, the content of all nutrients exceeded control. Weather conditions of the vegetation period have a great influence on the nutrient content. The least amount of nitrogen and potassium was in the vegetative mass of crops in favorable years. The most intensive reduction of nitrate nitrogen after the introduction of chemical means of plant protection occurs in dry years. The content of nitrate nitrogen, phosphorus, potassium in millet grain, spring wheat, chickpeas, coriander and oats in variants with the use of chemical plant protection products (herbicides, insecticides) was at or above the control level. It has been established that herbicides and insecticides did not adversely affect plant development conditions in biochemical processes in plants. 